\title{
International Drilling to Recover Aquifer Sands (IDRAs) and Arsenic Contaminated Groundwater in Asia
}

by Alexander van Geen

A group of forty-four scientists and students from fourteen countries met on 25-27 April 2011 in Hanoi, Vietnam to set the stage for a new continental drilling program focused on the groundwater arsenic (As) problem in Asia. Half of the participants were from low and lower-middle income countries directly facing the major health threat of elevated groundwater As. This issue affects over 100 million rural inhabitants across Bangladesh, Cambodia, China, India, Myanmar, Nepal, Pakistan, and Vietnam who rely on shallow (typically <100-m-deep) wells as their main source of drinking water (Ravenscroft et al., 2009). Groundwater from these areas can contain As at levels that have been shown to cause deadly cancers and cardiovascular disease and to inhibit the mental development of children (Smith, A.H. et al., 2000; Wasserman et al., 2004; Kapaj et al., 2006; Argos et al., 2010).

There is broad agreement within the international scientific community that reductive dissolution of iron (Fe) oxyhydroxides in river basins across Asia is a key factor leading to widespread occurrence of As in shallow groundwater (Kinniburgh and Smedley, 2001; Fendorf et al., 2010). The underlying reason is the strong affinity of As for Fe oxyhydroxides that results in As accumulation on the coatings of suspended particles. Upon burial, As is released to groundwater by microbially mediated dissolution of these Fe oxyhydroxides. There is a lack of necessary data, however, to discern the relative importance of other mechanisms, including the role of local vs. advected sources of reactive organic carbon that drive aquifers towards reduction. There is also a lack of critical information required to identify the cause of the extraordinary variability of groundwater As concentrations across a wide range of spatial scales (Fig. 1.) It is clear that this spatial variability is not directly controlled by the bulk As content of the sediment which, although not particularly elevated, is sufficient to increase groundwater As concentrations to over 1000 times the World Health Organization's guideline of $10 \mu \mathrm{g} \mathrm{L}^{-1}$ for As in drinking water if released.

Recent work reviewed at the International Drilling to Recover Aquifer Sands (IDRAs) workshop highlighted the importance of understanding the interactions between geology, hydrology, geochemistry, and microbiology that must be understood to understand and predict the release of As that occurs mostly in aquifers $<100 \mathrm{~m}$ deep (Fig. 1a). Because of the difficulty of distinguishing some of these processes, participants agreed to focus their efforts on the issue of greatest societal relevance, which is the vulnerability of those aquifers that are currently low in As (von Brömssen et al., 2007; Michael and Voss, 2008; Winkel et al., 2011). Tapping those aquifers, shallow or deep, that are low in As has had a much bigger impact in terms of lowering exposure than any other form of mitigation, including water treatment or rainwater harvesting, and it will likely continue to do so for the foreseeable future (Ahmed et al., 2006).

Workshop participants agreed that an effective approach to gaining a better understanding of the vulnerability of lowAs aquifers is to study pronounced lateral and vertical concentration gradients and determine whether such transitions could shift in response to massive groundwater pumping in some regions. In this context, one key question is whether a low-As aquifer is more likely to become contaminated because of inflow from a high-As zone or because of in situ As release triggered by a change in groundwater composition induced by massive pumping for irrigation or municipal and industrial use (Fig. 2). This is a critical distinction. A number of plausible mechanisms have been proposed by which changes in the flow or composition of groundwater in response to pumping could either increase or decrease the As levels in groundwater (Klump et al., 2006; Neumann et al., 2010; McArthur et al., 2010), but none have been demonstrated across a broad range of settings.

Workshop participants agreed that a decade-long integrated research program is required in order to identify the mechanisms that are most relevant to predicting the fate of low-As aquifers. A guiding hypothesis for such a program was formulated at the workshop as follows:

"The distribution of As in reducing groundwater is anchored to the local geology across a range of spatial scales and therefore naturally evolves on 100-1000 year time scales. The scale of human perturbations of the natural groundwater flow that threaten aquifers that are currently low in As on 10-yr timescales can be predicted by considering a limited set of parameters."

Initial studies would be focused on a subset of previously studied sites from which background information is already available, as well as a on series of new transects that are scientifically relevant but also cross the borders between affected countries, some of which are politically sensitive 
(e.g., Pakistan-India, India-Bangladesh, and CambodiaVietnam). The objective of in-depth study of selected sites would be to identify which minimum set of geological, hydrological, geochemical, and microbial parameters must be considered to make reasonably accurate predictions of the vulnerability of low-As aquifers across the affected region in the absence of a full-scale study.

A key factor that has impeded progress in understanding the processes regulating groundwater As levels is that matched samples of uncompromised groundwater and aqui- fer sediment from precisely the same interval are typically not available for detailed analysis and incubation. Participants agreed that a transportable drilling facility with new technology for collecting and processing paired groundwater and sediment samples under sterile and anoxic conditions would be an important catalyst for a long-term collaborative interdisciplinary research program across the affected region. The new technology is based on isolating a coring tube until the desired depth has been reached, followed by sealing the end of the coring tube before retrieval by in situ freezing.

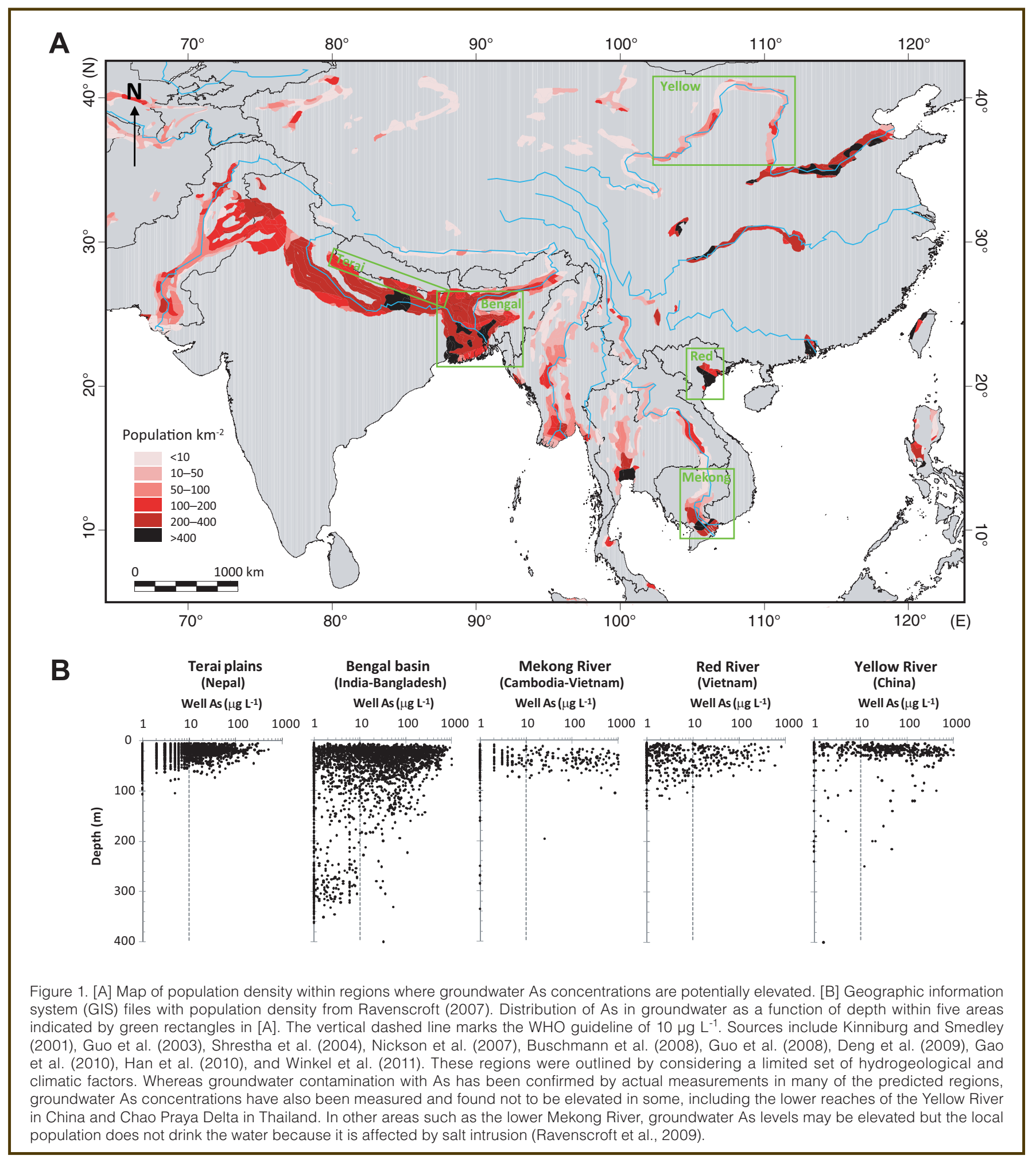


Such a drill rig, sampling tools, and a machine shop for repair and maintenance included with the mobile facility would fit in four 6-m shipping containers.

The proposed drilling facility would be complemented with a fifth containerized laboratory equipped to sterilize sampling tools, extrude aquifer samples anaerobically, analyze labile properties, and prepare samples for shipping to laboratories for further analyses. The facility would have the ability to test for sample contamination with drilling fluids using techniques developed under the Integrated Ocean Drilling Program (Smith, D.C. et al., 2000). The facility has been designed for sampling both groundwater and aquifer sediment from depths of up to $300 \mathrm{~m}$, which will be important to determine the fate of the particularly deep low-As aquifers that are increasingly relied on in the Bengal Basin (Fig. 1).

Over the next several months, workshop participants as well as interested scientists who could not join this particular meeting will prepare a full International Continental Scientific Drilling Program (ICDP) proposal for the January 2012 deadline. Key features were outlined at the Hanoi workshop, including identifying a viable management structure for prioritizing study sites, ensuring broad participation, standardizing methods, and securing supplemental funding. The group's likely strategy will be to focus during a first fiveyear phase on sites with sufficient geophysical and hydrological background information that are either unperturbed by groundwater pumping (e.g., portions of Vietnam or Cambodia) or so strongly perturbed by municipal pumping (e.g., around Kolkata, Dhaka, or Hanoi) that groundwater flow patterns are fairly predictable. Based on the new knowledge generated during the first phase, the group expects to be ready to study sites that are affected by more complex patterns of irrigation pumping in other regions in a second five-year phase. This multi-year and multi-country project is unique in scientific drilling, and it will require strong management, communication, and coordination. Participants agreed that annual workshops and support for scientists and students from countries affected by As to work in countries other than their own will be key to maintaining the momentum generated in Hanoi by providing a forum for planning and reviewing the latest findings.

\section{IDRAs Workshop Participants}

Australia: Bibhash Nath (University of Sydney); Bangladesh: Kazi Matin Ahmed (University of Dhaka),
Ashraf Ali Seddique (Jessore Science \& Technology University), Mohammad Tauhid-Ur-Rahman (Shahjalal University of Science \& Technology), Anwar Zahid (Bangladesh Water Development Board); Canada: Roger Beckie (University of British Columbia), Mario Bianchin (Lorax Environmental); China: Huaming Guo (China University of Geosciences); France: Laurent Charlet (University of Grenoble); Germany: Sebastian Behrens, Andreas Kappler (Eberhard-Karls-University Tuebingen), Harald Neidhardt, Thomas Neumann (Karlsruhe Institute of Technology), Thomas Wiersberg (Scientific Drilling ICDP), India: Sudipta Chakraborty (Kanchrapara College), Debashis Chatterjee (University of Kalyani), Syed Hillal Farooq (St.Xavier's College), Manoj Kumar, Sonnenchien Kushagra, Al Ramanathan, Chander Kumar Singh (Jawaharlal Nehru University), Abhijit Mukherjee (Indian Institute of Technology (IIT)Kharagpur); Japan: Harue Masuda (Osaka City University); Nepal: Jaya Kumar Gurung (Nepal Development Research Institute), Bishal Nath Upreti (Tribhuvan University); Pakistan: Abida Farooqi, Mehwish Ramzan (Fatima Jinnah Women University), Sweden: Prosun Bhattacharya (Royal Institute of Technology); Switzerland: Michael Berg, Rolf Kipfer, Lenny Winkel (Eawag); U.S.A.: Benjamin Bostick (Lamont-Doherty Earth Observatory), Karen Johannesson (Tulane University), Natalie Mladenov, Diana Nemergut (University of Colorado), Dennis Nielson (DOSECC), Peggy O’Day (University of California, Merced), David Smith, Athur Spivack (University of Rhode Island), Alexander van Geen (Lamont-Doherty Earth Observatory); Vietnam: Ngoc Son Nguyen (Vietnam National Assembly Committee), Thi Ha Nguyen (Centre of Water Resources Monitoring and Forecast), Pham Thi Kim Trang, Pham Hung Viet (Hanoi University of Science).

\section{Acknowledgments}

The ICDP and the U.S. National Science Foundation's Division of Earth Sciences provided partial support for this workshop.

\section{References}

Ahmed, M.F., Ahuja, S., Alauddin, M., Hug, S.J., Lloyd, J.R., Pfaff, A., Pichler, T., Saltikov, C., Stute, M., and van Geen, A., 2006. Ensuring safe drinking water in Bangladesh. Science, 314:1687-1688, doi:10.1126/science.1133146.

Argos, M., Kalra, T., Rahouz, P.J., Chen, Y., Pierce, B., Parvez, F., Islam, T., Ahmed, A., Rakibuz-Zaman, M., Hasan, R., 
Sarwar, G., Slavkovich, V., van Geen, A., Granziano, J., and Ahsan, H., 2010. Arsenic exposure from drinking water, and all-cause and chronic-disease mortalities in Bangladesh (HEALS): A prospective cohort study. The Lancet, 376 (9737):252-258, doi: 10.1016/S0140-3736(10)60481-3.

Buschmann, J., Berg, M., Stengel, C., Winkel, L., Sampson, M.L., Trang, P.T.K., and Viet, P.H., 2008. Contamination of drinking water resources in the Mekong delta floodplains: Arsenic and other trace metals pose serious health risks to population. Environ. Int., 34:756-764, doi:10.1016/j.envint. 2007.12.025.

Deng, Y., Wang, Y., and Ma, T., 2009. Isotope and minor element geochemistry of high arsenic groundwater from Hangjinhouqi, the Hetao plain, Inner Mongolia. Appl. Geochem., 24:587-599.

Fendorf, S., Michael, H., and van Geen, A., 2010. Spatial and temporal variations of groundwater arsenic in South and Southeast Asia. Science, 328:1123-1127, doi:10.1126/science.1172974.

Gao, C.R., Liu, W.B., Li, J.F., and Li, F., 2010. Modes of occurrence of arsenic in Quaternary sediments of the Hetao Plain. Geol. China, 37(3):760-770.

Guo, H., Wang, Y., Shpeizer, G.M., and Yan, S., 2003. Natural occurrence of arsenic in shallow groundwater, Shanyin, Datong Basin, China. J. Environ. Sci. Health, Part A, 38(11):2565-2580.

Guo, H., Yang, S., Tang, X., Li, Y., and Shen, Z., 2008. Groundwater geochemistry and its implications for arsenic mobilization in shallow aquifers of the Hetao Basin, Inner Mongolia. Sci. Total Environ., 393:131-144, doi:10.1016/j.scitotenv. 2007.12.025.

Han, S.B., Zhang, F.C., Zhang, H., Jia, X.F., He, J., and Li, X.F., 2010. An analysis of the distribution and formation of high arsenic groundwater in northern China. Geol. China, 37(3):747-753.

Kinniburgh, D.G., and Smedley, P.L., 2001. Arsenic contamination of ground water in Bangladesh, Final Report, vol. 2, BGS Technical Report WC/00/19, British Geological Survey, Keyworth, U.K., http://www.bgs.ac.uk/arsenic/bphase2/ reports.htm.

Klump, S., Kipfer, R., Cirpka, O.A., Harvey, C.F., Brennwald, M.S., Ashfaque, K.N., Badruzzaman, A.B.M., Hug, S.J., and Imboden, D.M., 2006. Groundwater dynamics and arsenic mobilization in Bangladesh assessed using noble gases and tritium. Environ. Sci. Technol., 40:243-250, doi:10.1021/ es051284w.

Kapaj, S., Peterson, H., Liber, K., and Bhattacharya, P., 2006. Human health effects from chronic arsenic poisoning - A review. J. Environ. Sci. Health, Part A, 41(10):2399-2428.

McArthur, J.M., Banerjee, D.M., Sengupta, S., Ravenscroft, P., Klump, S., Sarkar, A., Disch, B., and Kipfer, R., 2010. Migration of As, and ${ }^{3} \mathrm{H} / 3 \mathrm{He}$ ages, in groundwater from West Bengal: Implications for monitoring. Water Res., 44:4171-4185, doi:10.1016/j.watres.2010.05.010.

Michael, H.A., and Voss, C.I., 2008. Evaluation of the sustainability of deep groundwater as an arsenic-safe resource in the Bengal Basin. Proc. Natl. Acad. Sci. USA, 105:8531-8536, doi:10.1073/pnas.0710477105.

Neumann, R.B., Ashfaque, K.N., Badruzamman, A.B.M., Ali, M.A., Shoemaker, J.K., and Harvey, C.F., 2010. Anthropogenic influences on groundwater arsenic concentrations in Bangladesh. Nature Geosci., 3:46-52. doi: 101038/ NGEO685.

Nickson, R., Sengupta, C., Mitra, P., Dave, S.N., Banerjee, A.K., Bhattacharya, A., Basu, S., Kakoti, N., Moorthy, N.S., Wasuja, M., Kumar, M., Mishra, D.S., Ghosh, A., Vaish, D.P., Srivastava, A.K., Tripathi, R.M., Singh, S.N., Prasad, R., Bhattacharya, S., and Deverill, P., 2007. Current knowledge on the distribution of arsenic in groundwater in five states of India. J. Environ. Sci. Health A Tox. Hazard. Subst. Environ. Eng., 42:1707-1718, doi:10.1080/109345 20701564194.

Ravenscroft, P., 2007. Predicting the global extent of arsenic pollution of groundwater and its potential impact on human health. Unpublished report prepared for UNICEF, December 2007. Accessible online at: http://phys4.harvard.edu/ wilson/ arsenic/references/Ravenscroft_Prediction.pdf.

Ravenscroft, P., Brammer, H., and Richards, K., 2009. Arsenic Pollution: A Global Synthesis: Chichester, U.K. (WileyBlackwell). doi:10.1002/9781444308785.

Shrestha, C.R., Whitney, J.W., and Shrestha, K.B., 2004. The State of Arsenic in Nepal-2003: Kathmandu, Nepal (National Arsenic Steering Committee, Environment and Public Health Organization), 126 pages and CD-ROM.

Smith, A.H., Lingas, E.O., Rahman, M., 2000. Contamination of drinking-water by arsenic in Bangladesh: a public health emergency. Bulletin WHO 2000, 78(9):1093-1103.

Smith, D.C., Spivack, A.J., Fisk, M.R., Haveman, S.A., Staudigel, H., and Ocean Drilling Program Leg 185 Shipboard Scientific Party, 2000. Tracer-based estimates of drilling-induced microbial contamination of deep sea crust. Geomicrobiol. J., 17:207-219, doi:10.1080/01490450050121170.

von Brömssen, M., Jakariya, M., Bhattacharya, P., Ahmed, K.M., Hasan, M.A., Sracek, O., Jonsson, L., Lundell, L., and Jacks G., 2007. Targeting low-arsenic aquifers in groundwater of Matlab Upazila, Southeastern Bangladesh. Sci. Total Environ., 379:121-132, doi:10.1016/j.scitotenv.2006.06.028.

Wasserman, G.A., Liu, X., Parvez, F., Ahsan, H., Factor-Litvak, P., van Geen, A., Cheng, Z., Slavkovich, V., Hussain, I., Momotaj, H., and Graziano, J.H., 2004. Water arsenic exposure and children's intellectual function in Araihazar, Bangladesh. Environ. Health Perspect., 112:1329-1333, doi:10.1289/ ehp.6964.

Winkel, L.H.E., Trang, P.T.K., Lan, V.M, Stengel, C., Amini, M., Ha, N.T., Viet, P.H., and Berg, M., 2011. Arsenic pollution of groundwater in Vietnam exacerbated by deep aquifer exploitation for more than a century. Proc. Natl. Acad. Sci. USA, 108:1246-1251, doi:10.1073/pnas.1011915108.

\section{Author}

Alexander van Geen, Lamont-Doherty Earth Observatory (LDEO), Columbia University, 131 Corner, 61 Route 9W P.O. Box 1000, Palisades, N.Y. 10964-8000, U.S.A., e-mail: avangeen@1deo.columbia.edu.

\section{Related Web Link}

http://hanoi.icdp-online.org 